\title{
Identification of Criteria for Patient Prioritization in Two Specialized Rehabilitation Programs: A Consensus-Seeking Method
}

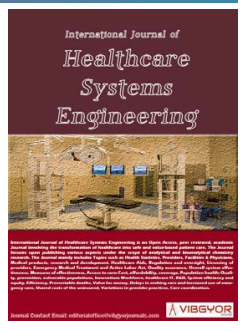

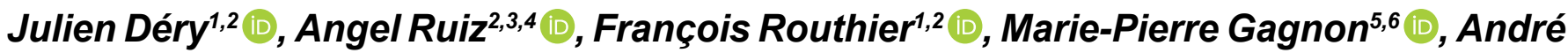 Côté $e^{3,6,7}\left(\mathbb{D}\right.$, Daoud Ait-Kadi ${ }^{2,4,8}\left(\mathbb{D}\right.$, Valérie Bélanger ${ }^{4,9}$ and Marie-Eve Lamontagne ${ }^{1,2^{*}}(\mathbb{D})$}

${ }^{1}$ Department of Rehabilitation, Université Laval, Québec, Canada

${ }^{2}$ Centre Interdisciplinaire de Recherche en Réadaptation et Intégration Sociale (CIRRIS), Québec, Canada

${ }^{3}$ Faculty of Business Administration, Université Laval, Québec, Canada

${ }^{4}$ Centre Interuniversitaire de Recherche sur les Réseaux d'entreprise, la Logistique et le Transport

(CIRRELT), Montréal, Canada

${ }^{5}$ Faculty of Nursing, Université Laval, Québec, Canada

${ }^{6}$ Centre de Recherche du CHU de Québec, Québec, Canada

${ }^{7}$ Centre de Recherche en Gestion des Services de Santé, Université Laval, Québec, Canada

${ }^{8}$ Department of Mechanical Engineering, Université Laval, Québec, Canada

${ }^{9}$ Department of Logistics and Operations Management, HEC Montréal, Montréal, Canada

\begin{abstract}
Patient prioritization, which is the process of ranking in a certain order based on various criteria, might be a good strategy to help manage access to healthcare services in a fair and equitable manner. It implies a decision-making process about prioritization criteria, and diverges substantially across programs. This process should thus be performed using a rigorous process that considers the various needs of the patients and evaluates them in a valid and reliable manner using prioritization tools carefully designed. In such tools, the prioritization criteria are often not standardized, not evidence-based or only based on individual clinical judgment. There is a need to document the criteria in rehabilitation programs. The aim of our study is to use a group method to obtain a consensus about patient prioritization criteria in two rehabilitation programs. We performed a group consensus-seeking method, Technique for Research of Information by Animation of a Group of Experts aiming to select prioritization criteria, which combines an individual and a group phase. Experts of both programs selected 10 criteria during a group discussion to prioritize patients in their respective programs. A group consensus method could promote a shared decision-making process between stakeholders to develop a prioritization tool in rehabilitation settings.
\end{abstract}

\section{Keywords}

Prioritization, Rehabilitation, Waiting lists, Criteria, Consensus

\footnotetext{
*Corresponding author: Dr. Marie-Eve Lamontagne, PhD, OT, Department of Rehabilitation, Université Laval, 1050, Avenue de la Médecine, Québec, G1V OA6; Centre Interdisciplinaire de Recherche en Réadaptation et Intégration Sociale (CIRRIS), IRDPQ - Bureau H-1402, 525, boul. Wilfrid-Hamel, Québec, G1M 2S8, Canada, Tel: (418)-529-9141, poste 2423, Fax: (418)-529-3548 Accepted: July 20, 2020; Published: July 22, 2020

Copyright: @ 2020 Déry J, et al. This is an open-access article distributed under the terms of the Creative Commons Attribution License, which permits unrestricted use, distribution, and reproduction in any medium, provided the original author and source are credited.

Déry et al. Int J Healthc Syst Eng 2020, 2:004
} 


\section{Background}

Wait times are a common consequence of limited access to healthcare services that are observed in a variety of rehabilitation settings such as homecare or community services [1-4], outpatient hospital-based departments $[1,2,5]$ and rehabilitation centres $[1,6]$. Patients who experience excessive wait times can suffer significant consequences, such as an increase of pain and impact on function, and deterioration in quality of life $[2,7]$. Consequently, waiting lists should be managed as fairly as possible to ensure that patients with greater or more urgent needs receive services ahead of those with less urgent need [8,9]. There is consequently an urgent need to find solutions to improve access to healthcare services, in contrast of a first-in firstout method, a wait list management strategy only based on a time-related criterion [10]. Patient prioritization is the process of ranking in a certain order based on various criteria $[9,11]$, such as patient needs. Rehabilitation service users have complex needs characterize by several social and physical factors related to their needs for care. It could thus be a good strategy to help manage access to healthcare and more specifically rehabilitation services in a fair and equitable manner [4].

Patient prioritization has been a strategy commonly used to manage access among a variety of healthcare services (e.g. cataract surgery, arthroplasty, children's mental health services) and in many countries, such as Canada, Spain and New Zealand [12-17]. Patient prioritization has also been used in rehabilitation, such as home care $[4,18,19]$, hospital outpatient departments [5] and mental health occupational therapy services [20]. Prioritization implies a decision-making process based on criteria according to which patient prioritization will be decided [21]. This process should thus be performed using a rigorous process that considers the various needs of the patients and evaluates them in a valid and reliable manner using prioritization tools carefully designed. However, as it is for other settings, the few studies presenting patient prioritization practises in a rehabilitation program suggest that prioritization criteria are often not standardized [4], not evidence-based $[5,18]$ or only based on individual clinical judgment $[5,18,19]$. The lack of robustness of the prioritization criteria used may represent a threat to its validity and usefulness, limiting the potential impact of prioritization systems upon the equity of rehabilitation services access.
The selection process of prioritization criteria is a very important step because it leads to improve reliability [19] and validity [22] of the prioritization tools in which criteria are applied. In elective surgery settings, prioritization criteria have been selected through a series of a panel of experts meetings, formed by surgeons, family physicians, representatives from health research and administration, users of healthcare services, and more [2325]. Some studies used a formal group consensus technique to develop priority criteria, such as the Delphi process method [26-28]. One study differs from others where authors used semi-structured interviews with surgeons to produce a set of criteria [29]. MacCormick, et al. [30] performed a systematic literature review aiming to document the priority scoring tools for elective surgery and what different factors/criteria are in use. They found that studies included generic criteria as well as specific ones [30]. More precisely, patient prioritization criteria among rehabilitation programs are usually determined by informal and individual consultations between clinicians within the program $[5,18,19]$. Eliciting criteria in rehabilitation settings becomes a complex task because these are not always based solely on the individual needs of patients, but may also be influenced by other factors, such as funding arrangements, specific aspects of the health service and patient/group pressures [11]. Raymond, et al. [18] showed the wide spectrum of criteria used in a rehabilitation setting, as they identified 48 main categories of criteria in prioritization tools used in 55 home care programs across Quebec. This highlights the importance of reaching a certain level of consensus for the resulting criteria to be applicable in practice and acceptable to the rehabilitation stakeholders.

In fact, little is known about the individual and group preferences for prioritization and there is a need to explicitly compare criteria elicited by individuals and groups for prioritization in highly multidisciplinary contexts, such as rehabilitation, where it is crucial to build a common vision. It would be relevant to describe the process to generate prioritization criteria from an individual to a group perspective, in order to understand how stakeholders can reach consensus about an organizational decision. Connolly [31] argue that various "constituencies", defined as any individual who may influence an organization, have their own point of view about the organization and they are all relevant to 
benefit the organization. Thus, the aim of our study is to obtain a consensus about patient prioritization criteria in two rehabilitation programs. The objectives are to describe individual preference about prioritization criteria, report the group consensus and to compare selections of criteria between an individual phase and a group phase.

\section{Methods}

\section{Study design and setting}

We conducted a case study [32] in two rehabilitation programs embedded in the Centre intégré universitaire de santé et de services sociaux de la Capitale-Nationale in Quebec City (Canada) between January to December 2018. Case studies allow for understanding dynamics in given settings and members of two rehabilitation programs agreed to participate in the study a driving evaluation program (DEP) and a compression garment manufacturing program (CGMP) for burn victims.

\section{Description of the programs}

The DEP offers a range of specialized rehabilitation services related to driving skills mostly to outpatient patients with physical and intellectual disabilities. A multidisciplinary team $(n=12)$ that includes occupational therapists, driving instructors, a neuropsychologist, a social worker, a clinical coordinator and a manager are involved in the program. Referrals come from other rehabilitation professionals who encounter driving-related problems with their patients. The clinical coordinator is the person in charge of the wait list, and she uses criteria to prioritize patients based on her experiences, her clinical judgment and the referral motives.

The CGMP customizes compression garments for burn victims during their inpatient or outpatient rehabilitation. Mainly occupational therapists ( $\mathrm{n}=$ $5)$ and tailors ( $n=3$ ) work together to fit the garment to patients' needs. Plastic surgeons from acute care hospital refer patients to CGMP after their skin graft if they judge it is necessary for healing process. Other professionals from hospital setting are in contact with the burn victims and participate in the general rehabilitation process, such as physiotherapists and nurses. A clinical coordinator manages clinicians' caseloads and ensures the smooth running of the program. Three managers are involved partly to supervise the teams, one for acute care, one for multidisciplinary rehabilitation and one for compression garment tailors. This pro- gram already used an in-house prioritization tool to designate a priority score to each patient waiting for a compression garment. Occupational therapists assign patient prioritization scores based in this tool and they discuss with tailors to organize appointments and garment delivery.

Both programs are located under the same healthcare organization, which a group of institutions that provides a wide range of healthcare services to the population of the Greater Quebec City region. The programs have been chosen because of their long waiting lists and interests of stakeholders to develop a new prioritization tool designed for their clinical setting. We also chose one program delivering services (driving evaluation) and another customizing a product (compression garment).

\section{Ethical considerations}

Centre intégré universitaire de santé et de services sociaux de la Capitale-Nationale Ethics Committee granted full ethics approvals (EMP-2017-587) and Centre hospitalier universitaire de Québec-Université Laval Ethics Committee approved the project as well to probe service providers from their institution. All participants signed a consent form prior to participating which presented potential consequences of the study. They were free to decline the questionnaire invitation and to quit the project whenever they wanted.

\section{Participants}

We recruited participants from each rehabilitation program, such as patients, clinicians, coordinators and managers. We aimed to recruit between 6 and 10 healthcare service providers and as many patients from each rehabilitation program. Clinical coordinators facilitated recruitment by targeting potential participants within their program (patients, clinicians and managers). They first contacted patients to ask if they were interested to be contacted to receive more information about the study. Then, we reached participants by phone to give more details about the study and to explain their contribution to the project. Inclusion criteria for patient participants were to be 18 years of age or older, to have physical disabilities, to be on the waiting list or have received services from the program in the past year and to speak French. We directly contacted clinicians and managers by email to explain the project and to obtain their consent to participate. They were included in the study if they 
worked in the program for at least 6 months and for a minimum of 3 days/week.

\section{Procedure}

A group consensus-seeking method named The Technique for Research of Information by Animation of a Group of Experts (TRIAGE) [33] was performed aiming to select prioritization criteria. This technique aims to bring a group of informed stakeholders (known as "experts") to individually produce a set of options (known as "criteria", in this study), and then collectively seek consensus in the selection of a subset of these criteria. The technique is thus a two-step process, which combines a data production and collection phase, taking part at the individual level, followed by a group consensus-seeking phase. It differs from other consensus methods, such as Delphi technique that implies multiple consultations process and consensus results by a mathematical decision.

Individual data production: We sent a webbased questionnaire using an online survey platform (Lime Survey) (see Supplementary File 1 for a copy of this questionnaire). The platform uses email addresses to send the link to the questionnaire. Participants must enter an invitation code provided in the email to have access to the questionnaire. A maximum of three invitation emails was sent if necessary, with one-week intervals. A research team member (master student) designed the questionnaire, activated initial and reminder emails sending and collected answers for analysis. The questionnaire aims to document individual patient prioritization criteria that should be used in each program. It included only one open-ended question asking to suggest multiple criteria (between 5 and 10) that participants considered most important for patient prioritization. Sociodemographic questions were included at the end of the electronic questionnaire. Research team members tested a draft version of the questionnaire for clarity and relevance. We conducted an inductive thematic analysis of individual answers obtained from an online questionnaire using analysis software (Dedoose). We first familiarized with the data and then we generated codes based on the recurrent themes (criteria in our case). Individual answers of each expert were coded and combined in a single set of criteria and an external reviewer validated groupings of criteria included in the set.

Group data production: Clinicians, coordinators and managers of each program participated in a group meeting (one for each program). We explained the group consensus process and sum-
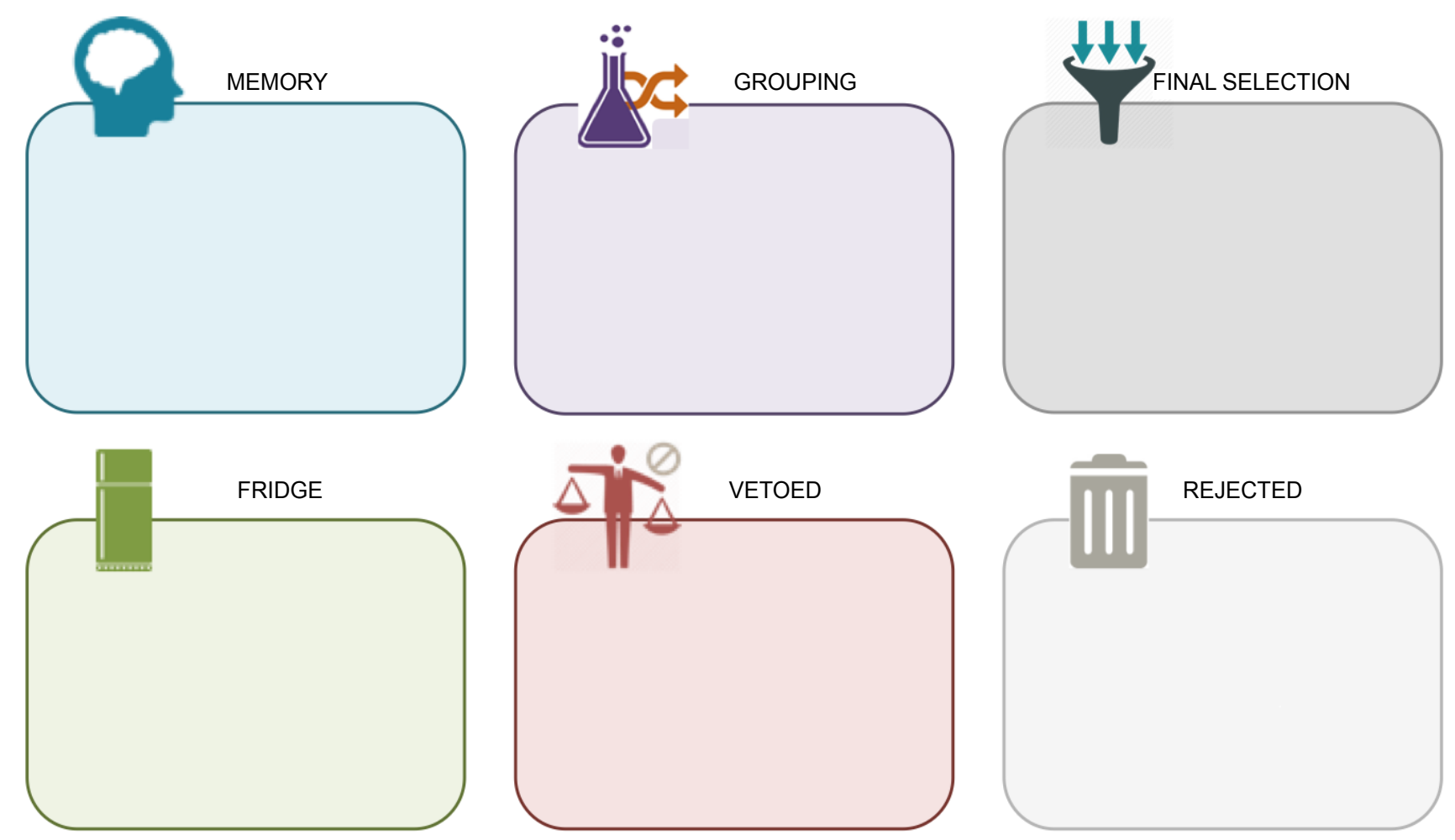

Figure 1: Categories organizing criteria during TRIAGE group phase. 
marized the context of the project and the research question before discussions began. We divided a wall space in six categories: "Memory", "Grouping", "Fridge", "Vetoed", "Rejected" and "Final selection" (Figure 1). We put criteria under the "Memory" section before the discussions started. The aim was to sort all the criteria from the "Memory" category to the "Final selection" category. We explained verbally all categories and all criteria to ascertain the meaning of each as necessary.

A group moderator facilitated discussions and moved criteria from a category to another. When a criterion was unanimously considered relevant to consider in patient prioritization, it was moved to
"Final selection" section. If the group considered a criterion irrelevant, it was moved under the "Rejected" section. Under the "Grouping" category, participants reorganized existing criteria by merging them, dividing them or adding one. Criteria that could not be readily categorized were placed to the "Fridge" to avoid time-consuming discussions on a single criterion. If agreement on these criteria could not be reached by the end of the meeting, they were placed in the "Vetoed" section. If necessary, external experts would discuss the elements put under the "Vetoed" label after the group activity regarding the inclusion or exclusion of the vetoed criteria. All discussions were audio

Table 1: Sociodemographic and occupational information about provider participants.

\begin{tabular}{|c|c|c|c|}
\hline & & $\begin{array}{l}\text { Compression garment } \\
\text { manufacturing providers }(n=10)\end{array}$ & $\begin{array}{l}\text { Driving evaluation } \\
\text { providers }(n=8)\end{array}$ \\
\hline \multirow[t]{2}{*}{ Age (years) } & Mean & 45.8 & 44.8 \\
\hline & SD & 9.5 & 9.2 \\
\hline \multirow[t]{2}{*}{ Sex } & Men & - & 1 \\
\hline & Women & 10 & 7 \\
\hline \multirow[t]{2}{*}{ Workplace } & Rehabilitation center & 8 & 8 \\
\hline & Hospital & 2 & - \\
\hline \multirow[t]{3}{*}{ Program } & Acute care & 2 & - \\
\hline & Rehabilitation & 4 & 8 \\
\hline & Technical aids & 4 & - \\
\hline \multirow[t]{5}{*}{ Occupation } & Tailor & 3 & - \\
\hline & Manager & 2 & 1 \\
\hline & Driving instructor & - & 1 \\
\hline & Coordinator & 1 & 1 \\
\hline & Clinician & 4 & 5 \\
\hline \multirow{2}{*}{$\begin{array}{l}\text { Years of experience in } \\
\text { occupation }\end{array}$} & Mean & 21.2 & 19.8 \\
\hline & SD & 9.0 & 10.3 \\
\hline \multirow{2}{*}{$\begin{array}{l}\text { Years of experience in } \\
\text { program }\end{array}$} & Mean & 12.7 & 4.6 \\
\hline & SD & 8.9 & 4.0 \\
\hline \multirow{8}{*}{$\begin{array}{l}\text { Education/Area of } \\
\text { expertise }\end{array}$} & Administration & - & 1 \\
\hline & $\begin{array}{l}\text { Education and road } \\
\text { safety }\end{array}$ & - & 1 \\
\hline & Fashion design & 3 & - \\
\hline & Neuropsychology & - & 1 \\
\hline & Nursing & 2 & - \\
\hline & Occupational therapy & 3 & 4 \\
\hline & Physiotherapy & 2 & - \\
\hline & Social work & - & 1 \\
\hline
\end{tabular}


recorded in order to help subsequent analysis. The aim of each group meeting was to obtain consensus about selection of 8 to 12 prioritization criteria.

\section{Analysis}

TRIAGE method allows relevant results immediately upon completion of the session, which do not require a sophisticated analysis [33]. As an integral part of the method, group discussions enhance the relevance of TRIAGE as they allow the participants to form a collectively informed comprehensive understanding of the phenomenon at hand while empowering them to make choices, by opposition to mathematical or researcher-dictated choices. Criteria within the "Final selection" and "Vetoed" categories are the primary results of the group exercise. We listened to audio recordings many times to extract relevant discussions that could explain the decision-making process and consensus choices of prioritization criteria. We linked those quotes to each criterion.

\section{Results}

\section{Individual data production}

We sent an email request to 24 rehabilitation service providers and 20 patients. A total of 20 providers and 11 patients answered the electronic questionnaire, which represents a participation rate of $83 \%$ and $55 \%$ respectively. Table 1 shows sociodemographic and occupational characteristics of providers. We had a broad range of providers, as clinicians, managers, coordinators and others such as tailors (who prepare compression garments) and driving instructors (who educate patients about driving techniques). Table 2 presents sociodemographic characteristics of patients participating in the study.

Figure 2 presents the 22 criteria proposed from DEP stakeholders and the 27 criteria from CGMP individually suggested by participants. We highlighted the fact that 8 criteria, presented in the central space, were elicited from stakeholders in both two programs.

\section{Group phase}

As some criteria were combined and modified through stakeholders' discussions during the group phase, some others were put away to obtain a final selection of prioritization criteria. In the DEP group, 8 experts narrowed the list of 22 criteria to a final selection of 10 criteria to prioritize patients in their rehabilitation program. In the CGMP group, 10 experts selected 10 criteria from the initial list of 27 proposed criteria. Table 3 shows the final criteria selection by group consensus for each program. Veto and Fridge sections were empty at the end of the group meetings.

Group discussions in DEP led to a modification of three criteria, "having children" to "parenting responsibilities", "degenerative aspect" to "degenerative disease" and "age" to "kid with disability as passenger". This group also created a new criterion from discussions as they chose to prioritize patients with ALS. For CGMP, they modified the criterion "time since referral" to be more representative of their context, i.e. "time since ordering garment". They also change wording of "hypertrophic scars" into a more global criterion, i.e. "functional impact

Table 2: Sociodemographic characteristics of patients in each program.

\begin{tabular}{|c|c|c|c|}
\hline & & $\begin{array}{l}\text { Compression garment } \\
\text { manufacturing patients }(n=5)\end{array}$ & $\begin{array}{l}\text { Driving evaluation } \\
\text { patients }(n=6)\end{array}$ \\
\hline \multirow[t]{5}{*}{ Age } & 30-39 & 1 & 2 \\
\hline & $40-49$ & 3 & 1 \\
\hline & $50-59$ & - & 1 \\
\hline & $60-69$ & 1 & - \\
\hline & $70-79$ & - & 2 \\
\hline \multirow[t]{2}{*}{ Sex } & Men & 1 & 4 \\
\hline & Women & 4 & 2 \\
\hline \multirow[t]{3}{*}{ Waiting situation } & On the waitlist & - & 2 \\
\hline & Receiving services & 4 & 1 \\
\hline & Already received services & 1 & 3 \\
\hline
\end{tabular}




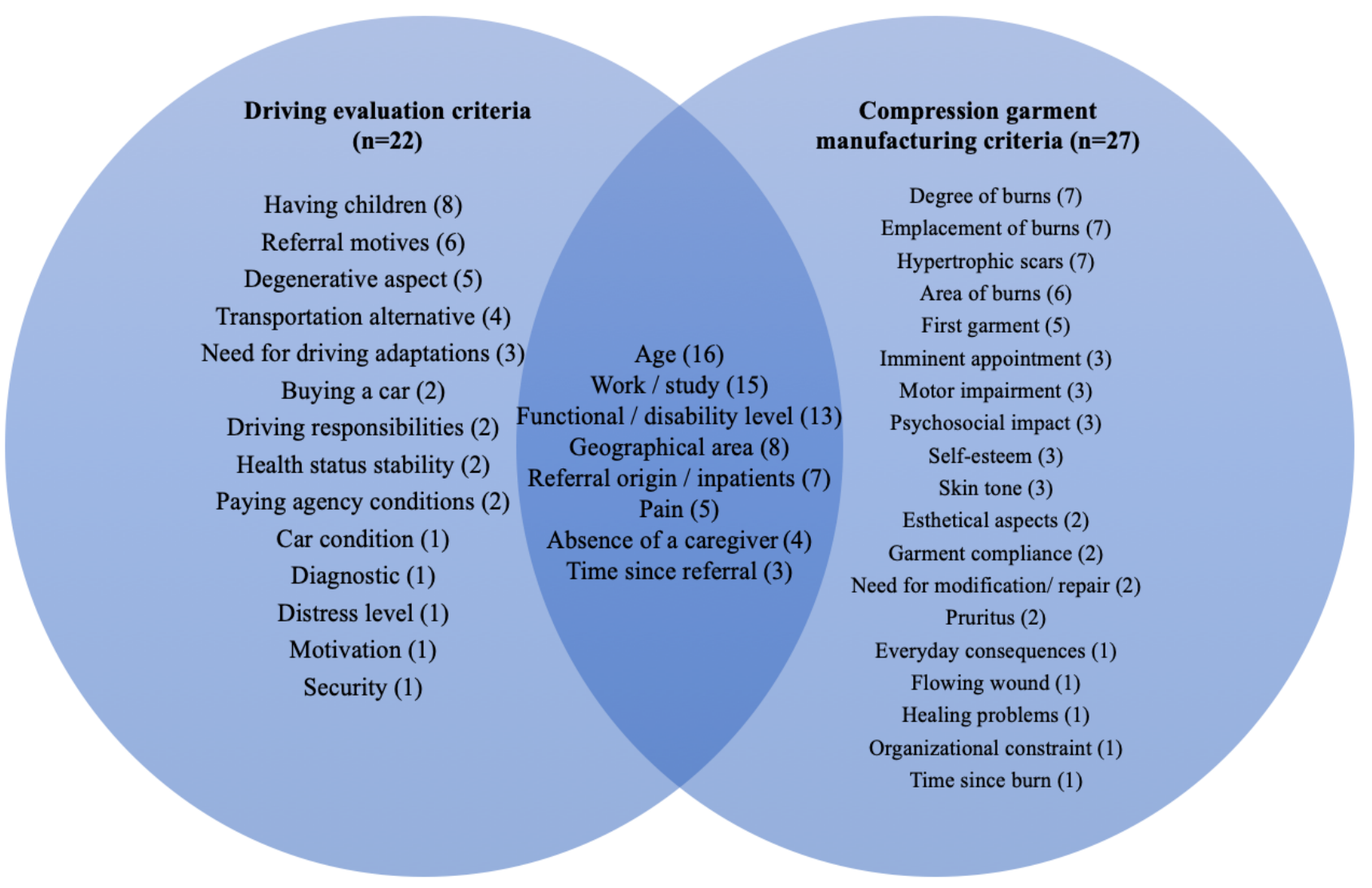

Figure 2: Criteria sorted by individually based recurrences.

Table 3: Criteria selected by group consensus for each rehabilitation program.

\section{Driving evaluation program}

Accessibility to public transportation

Amyotrophic lateral sclerosis (ALS)

Car condition

Degenerative disease

Kid with disability as passenger

Parenting responsibilities

Presence of a caregiver

Referral origin

Time since referral

Work/study

risks". From our results, we observed that criteria repeated more often in the individual phase are not necessarily those selected by group consensus. For example, "referral motives" was excluded from selection, but it was mentioned by 6 out of 14 stakeholders, as well as "functional or disability level" that was proposed by 13 out of 31 stakeholders from both programs. The opposite is also true: some criteria chosen from group consensus were only mentioned by less than $20 \%$ of stakeholders

\section{Compression garment manufacturing program} Age

Area of burns

Degree of burns

Emplacement of burns

First garment

Functional impact risks

Need for modifications/ repairs

Skin tone

Time since injury

Time since ordering garment

in the individual phase, such as "car condition", "absence of caregiver" and "time since referral" for DEP group, and "skin tone", "need for modification/repair" and "time since burn" for CGMP.

\section{Motives of group decision}

While participants discussed about which prioritization criteria are most relevant in their clinical setting, those discussions helped to reach consensus by modifying and combining terms. Participants 
of the DEP group agreed to choose a criterion under the same label regarding the access of transportation alternatives for patients. One participant stated, "We can combine absence of a caregiver and transportation alternatives, because in our program, it's kind of the same. As well as the geographical area where they live, because it has an impact on accessibility of a transport." Another participant answered, "I think we can group it under the same criterion, which is transportation alternatives."

As shown in Table 3, participants of the DEP group chose to include the condition of the user's car as a prioritization criterion. This choice means that a criterion that was not recurrently mentioned individually can still lead to a consensus selection. A participant expressed, "We would prioritize someone who has an obsolete equipment or car, versus a vehicle that is in good condition. So it's car condition, the criterion." Another participant confirmed, "Yes, the person who has an obsolete adapted car, he will get services before the others."

A criterion was first seen as unusual and was initially proposed by only three participants, but seemed to reach consensus after the group session. Two participants discussed, "Skin tone is very important, it's unavoidable." "We prioritize based on skin colour?" "It is proven in the literature, they have more risks of hypertrophy. It is clearly a personal factor that could accentuate skin hypertrophy. So, skin tone is the real term that we need to use to prioritize patients."

Participants of CGMP group discussed deeply about time-related criteria, and they finally reached consensus to include two distinct criteria which are time since burn and time since ordering the garment. Two participants argued, "Time since burn and time since referral are not the same. I think we need to include them." "Time since referral, is it related to the date of our referral or the one from the surgeon?" "It is the date when we sent the order form, because the date that we receive the referral from the surgeon is not linked to the needs of the patient. So, we need to change the term, it is time since ordering the garment."

\section{Discussion}

Identification of prioritization criteria is an important step, if not the most important, regarding prioritization decisions [21]. This choice of prioritization criteria is a complex task [11] that should be performed through a valid method taking into account a broad range of perspectives $[5,18,34]$. The goal of our case study was to obtain a consensus about patient prioritization criteria in two rehabilitation programs.

In our study, we performed the TRIAGE method, which allowed stakeholders to discuss and reach consensus regarding prioritization criteria for rehabilitation programs. We asked a group of experts to produce a list of criteria that can be used to prioritize patients in their respective rehabilitation program. We found that criteria elicited from an individual level can greatly differ from a group consensus level and that group consensus is useful to overcome individual differences. Repetitions of a criterion in the individual phase do not necessarily guarantee of a selection in group sessions. Discussions generated addition, suppression, combination and division of criteria, producing criteria that were shared and accepted by the groups.

There are many consensus methods used in healthcare research, main ones are Delphi technique, nominal group technique, consensus development conference and RAND/UCLA [35]. Studies describing development of prioritization criteria have mostly used Delphi techniques [2628]. TRIAGE differs from these methods, because it allows participants to combine an individual data production to a face-to-face group discussion in order to reach a consensus. The biggest strength of this technique is that it allows constituencies to discuss about their own vision - in our study, this led to discussions about which criteria are most relevant for patient prioritization in each program. As mentioned by Lamontagne, et al. [36], despite the fact that there is no empirical evidence that this technique is more valid or beneficial than other consensus-building techniques, we believe that the discussion phase of the method generates results that could be more acceptable for all participants and that could increase adherence to the prioritization tools to be developed.

Our results show that in each of our two cases, these discussions led to a common vision about prioritization criteria. Participants of neither group used the "Veto" and "Fridge" sections, which mean that they were able to reach a final selection of criteria facilitated by the consensus process. Group sessions promoted sharing ideas about the question of prioritization that one could have not thought 
during the individual questionnaire. Our groups were heterogeneous, having clinicians, managers, clinical coordinators, and a variety of professions represented. Thus, it is normal that each stakeholder did not have the same vision about an organizational question. This could justify the use of faceto-face group discussions in order to compare each vision and to stimulate different points of view, because participants could explain their points of view and argued their choice to other participants.

Each group chose 10 criteria, and two of those are similar between groups, but not identical. Both groups selected time-related criteria, i.e. "time since referral", "time since injury" and "time since ordering garment", and an age-related criterion, i.e. "kid with disability as passenger" and "age". Except those, all other criteria were different and specific to their respective services provided or users of the program. These results are consistent with other findings in elective surgery settings [30], having more tools with specific criteria and that they are mainly determined through consensus methods. Hadorn and colleagues [21] differentiated priority on the basis of clinical and non-clinical factors, because they stated that clinicians take non-clinical factors, such as age, patients' ability to work, to provide care to dependents or to live independently, into account when determining relative priority on waiting lists. Participants of our groups selected clinical criteria, such as ALS, degenerative disease or burn injury. As an example, in the context of driving evaluation services, criteria related to degenerative conditions, such as ALS, were emphasized by participants because of the rapid loss of dependence to driving. Non-clinical criteria, such as parenting responsibilities, presence of a caregiver and age were mentioned by participants. Thus, we can find some similarities between patient prioritization criteria, even if these are not exactly the same from a tool to another. These findings can benefit future development of patient prioritization tools by suggesting to include generic, specific, clinical and non-clinical criteria.

Few studies focus on the identification of prioritization criteria in rehabilitation settings. Most prevalent referral prioritization criteria for home care occupational therapy (OT) related to client's situation were pressure sore, palliative care, falls, safety risk, problems with activities of daily living, discharge from hospital requiring OT intervention, caregivers, transfers and risk of institutionalization [18]. Mifflin and Bzdell [37] developed a prioritization tool to help physiotherapists working in remote areas managed their caseloads, so they set a priority order based on 7 main client groups treated by physiotherapy services (e.g. inpatients, paediatric clients, clients at risk of falls, orthopaedic conditions, chronic conditions). They performed a literature and guidelines reviews, and interviews with physiotherapists working in remote areas [37]. Heasman and Morley [20] proposed prioritization protocols with 12 criteria to promote efficient and effective allocation of mental health occupational therapy resources. Criteria elicited in this study were very specific to mental health services, such as aggressive behaviour, non-accidental self-injury and problem-drinking. However, generic criteria are also used, such as having problems with activities of daily living and problems with occupation and activities. These findings corroborate our own results related to specific and generic criteria to prioritize patients in rehabilitation settings. Altogether, these studies showed that prioritization criteria used in clinical rehabilitation settings are different from one setting to another. Some are worth taking more into consideration for common use such as criteria related to age, to functional problems and to caregivers, as these seem to be used in the majority of prioritization processes.

An effort to base prioritization criteria on a robust process, such as literature review and consultation with stakeholders, increase the validity of prioritization tools and improve equity of access to services [18]. Raymond, et al. [18] showed that consultations of the scientific literature or service users are lacking parts in the development process of prioritization tools in home-based occupational therapy programs. However, studies mentioned previously $[20,37]$ performed literature reviews and then interviews or focus groups to elicit criteria through consultations with physiotherapists or occupational therapists. The variety of methods used to identify prioritization criteria and to develop prioritization tools in rehabilitation setting suggests that these processes are unclear and not standardized. We can contrast these findings with other studies that took place in elective surgery services for example, where development processes tend to follow clearer steps, such as literature reviews, Delphi consultations with surgeons and general physicians, and quality assessments of the prioritiz- 
ation tools $[22,28,38,39]$. Studies reporting evaluation of these tools demonstrated generally good reliability and validity $[38,39]$. No similar study has been performed in rehabilitation settings, so there is an urgent need of evidence to support development processes in order to have valid and accepted prioritization tools improving equity of access in rehabilitation programs.

We acknowledge that our study has some limits. First, results about criteria used may not be generalizable because there are based only on case studies in two rehabilitation programs and that the sample may be small, especially regarding the group of patients. Second, we cannot state, without any doubt, that criteria selected represent all stakeholders' perspective because some might have not expressed their perceptions by fear of judgment or other reasons. In fact, we did not analyze group dynamics during group data collection, and these can surely impact participation of all experts. It is also difficult to support that TRIAGE is the best technique to identify prioritization criteria. More studies are needed to document and to detail the development process of prioritization criteria in rehabilitation programs. Third, a literature review prior to stakeholders' consultations could have benefitted the criteria identification process. However, this study represents a first step of many more towards the development of a shared decision-making process to rally differing perspectives concerning patient prioritization criteria and tools in rehabilitation settings. We acknowledge that a larger consultation with multiple stakeholders about prioritization, including patients and lay people, would provide a better insight of waiting list management in specialized healthcare settings.

\section{Conclusion}

Identification and selection of patient prioritization criteria in rehabilitation settings can be a complex task. A consensus method could be a relevant technique to facilitate this decision in multidisciplinary teams, such as rehabilitation programs. We highlight the fact that criteria differ between rehabilitation programs because most are specific to the services offered, but some similarities in generic criteria exist and must be taken into account in prioritization processes. Further research is needed in similar and different settings to validate our findings in order to standardize prioritization practice and to promote fair and equitable access to rehabilitation services.

\section{Funding}

This study was funded by Fonds de recherche du Québec Nature et Technologie. JD received a study grant from the Centre interdisciplinaire de recherche en réadaptation et intégration sociale (CIRRIS) to conduct this study. MPG, FR and MEL are Fonds de recherche du Québec Santé Research Scholar.

\section{References}

1. Delaurier A, Sasha B, Raymond MH, Debbie EF (2013) Wait times for physical and occupational therapy in the public system for people with arthritis in Quebec. Physiotherapy Canada 65: 238-243.

2. Passalent LA, Landry MD, Cott CA (2009) Wait times for publicly funded outpatient and community physiotherapy and occupational therapy services: Implications for the increasing number of persons with chronic conditions in Ontario, Canada. Physiotherapy Canada 61: 5-14.

3. Passalent LA, Landry MD, Cott CA (2010) Exploring wait list prioritization and management strategies for publicly funded ambulatory rehabilitation services in Ontario, Canada: Further evidence of barriers to access for people with chronic disease. Healthcare Policy 5: e139-e156.

4. Raymond MH, Demers L, Feldman DE (2016) Waiting list management practices for home-care occupational therapy in the province of Quebec, Canada. Health \& Social Care in the Community 24: 154-164.

5. Laliberté M, Debbie EF, Bryn WJ, Matthew H (2018) Operationalizing wait lists: Strategies and experiences in three hospital outpatient physiotherapy departments in Montreal. Physiotherapy Theory and Practice 34: 872-881.

6. Greater Toronto Area Rehabilitation Network (2003). Measuring and managing supply and demand: A waiting list information management proposal for musculoskeletal rehabilitation in the Greater Toronto area.

7. Lynch ME, Fiona C, Alexander JC, Michael JD, David $G$, et al. (2008) A systematic review of the effect of waiting for treatment for chronic pain. Pain 136: 97116.

8. Cerdá E, de Pablos L, Rodriguez MV (2013) Waiting lists for surgery. In: Patient flow: Reducing delay in healthcare delivery, Springer: Boston, USA, 197-227.

9. Noseworthy T, McGurran J, Hadorn D (2003) Waiting for scheduled services in Canada: Development of priority-setting scoring systems. Journal of Evaluation in Clinical Practice 9: 23-31. 
10.Escobar A, José MQ, Marta G, Amaia B, Berta I (2009) Waiting list management: Priority criteria or first-in first-out? A case for total joint replacement. Journal of Evaluation in Clinical Practice 15: 595-601.

11. Harding K, Taylor N (2013) Triage in nonemergency services. In: Patient flow: Reducing delay in healthcare delivery, Springer, Boston, USA, 229-250.

12.Cawthorpe D, Abdul R, Derryck HS, Barbara CS, John JM, et al. (2007) Priority-setting for children's mental health: Clinical usefulness and validity of the priority criteria score. Journal of the Canadian Academy of Child and Adolescent Psychiatry 16: 18-26.

13.De Coster C, Stewart M, Rollin B, John M, Tom N (2007) The western canada waiting list project: Development of a priority referral score for hip and knee arthroplasty. Journal of Evaluation in Clinical Practice 13: 192-197.

14.Smith DH, Hadorn DC, Steering Committee of the Western Canada Waiting List Project (2002) Lining up for children's mental health services: A tool for prioritizing waiting lists. Journal of the American Academy of Child and Adolescent Psychiatry 41: 367-376.

15. Hansen P, Hendry A, Naden R, Ombler F, Stewart R (2012) A new process for creating points systems for prioritising patients for elective health services. Clinical Governance 17: 200-209.

16.Comas $M$, Xavier $C$, Lorena $H$, Rubén R, Francesc $C$, et al. (2008) Discrete-Event simulation applied to analysis of waiting lists. Evaluation of a prioritization system for cataract surgery. Value in Health 11: 1203-1213.

17. Tebe C, Merce C, Paula A, Maite SD, Alejandro A, et al. (2015) Impact of a priority system on patients in waiting lists for knee arthroplasty. Journal of Evaluation in Clinical Practice 21: 91-96.

18. Raymond MH, Feldman D, Prud'homme MP, Demers L (2013) Who's next? Referral prioritisation criteria for home care occupational therapy. International Journal of Therapy and Rehabilitation 10: 580-588.

19. Harding KE, Nicholas FT, Sandra GL, Vicki LW (2010) Prioritizing patients for community rehabilitation services: Do clinicians agree on triage decisions? Clinical Rehabilitation 24: 928-934.

20. Heasman D, Morley M (2012) Introducing prioritisation protocols to promote efficient and effective allocation of mental health occupational therapy resources. British Journal of Occupational Therapy 75: 522-526.

21. Hadorn DC, Steering Committee of the Western Canada Waiting List Project (2000) Setting priorities for waiting lists: Defining our terms. Canadian Medical Association Journal 163: 857-860.

22. Escobar A, Marta G, José MQ, Amaia B, Berta I (2009) Validation of a prioritization tool for patients on the waiting list for total hip and knee replacements. Journal of Evaluation in Clinical Practice 15: 97-102.

23.Taylor MC, Hadorn DC, Steering Committee of the Western Canada Waiting List Project (2002) Developing priority criteria for general surgery: Results from the Western Canada Waiting List Project. Canadian Journal of Surgery 45: 351-357.

24.Romanchuk KG, Suren S, David CH, Steering Committee of the Western Canada Waiting List Project (2002) Developing cataract surgery priority criteria: Results from the Western Canada Waiting List Project. Canadian Journal of Ophthalmology 37: 145154.

25.Arnett G, Hadorn DC, Steering Committee of the Western Canada Waiting List Project (2003) Developing priority criteria for hip and knee replacement: Results from the Western Canada Waiting List Project. Canadian Journal of Surgery 46: 290-296.

26.Quintana JM, Escobar A, Bilbao A (2006) Explicit criteria for prioritization of cataract surgery. BMC Health Services Research 6: 24.

27. Naylor C, Williams J (1996) Primary hip and knee replacement surgery: Ontario criteria for case selection and surgical priority. BMJ Quality \& Safety 5: 20-30.

28.Escobar A, Jose MQ, Amaia B, Berta IB (2007) Development of explicit criteria for prioritization of hip and knee replacement. Journal of Evaluation in Clinical Practice 13: 429-434.

29. MacCormick A, Macmillan A, Parry B (2004) Identification of criteria for the prioritisation of patients for elective general surgery. Journal of Health Services Research \& Policy 9: 28-33.

30. MacCormick AD, Collecutt WG, Parry BR (2003) Prioritizing patients for elective surgery: $A$ systematic review. ANZ Journal of Surgery 73: 633-642.

31.Connolly T, Conlon EJ, Deutsch SJ (1980) Organizational effectiveness: A multiple-constituency approach. Academy of Management Review 5: 211218.

32.Yin RK (2003) Case study research: Design and methods (Applied sociological research methods). Thousand Oaks, Sage publications.

33.Gervais M, Pépin G (2002) TRIAGE: A new group technique gaining recognition in evaluation. Evaluation Journal of Australasia 2: 45-49. 
34. Raymond MH, Demers L, Feldman DE (2018) Differences in waiting list prioritization preferences of occupational therapists, elderly people, and persons with disabilities: A Discrete Choice Experiment. Archives of Physical Medicine and Rehabilitation 99: 35-42.

35. Bourrée FP, Michel, Salmi LR (2008) Méthodes de consensus: Revue des méthodes originales et de leurs grandes variantes utilisées en santé publique. Revue d'Epidémiologie et de Santé Publique 56: 415423.

36.Lamontagne ME, Routhier F, Auger C (2013) Team consensus concerning important outcomes for augmentative and alternative communication assistive technologies: A pilot study. Augmentative and Alternative Communication 29: 182-189.

37.Mifflin TM, Bzdell M (2010) Development of a physiotherapy prioritization tool in the baffin region of nunavut: A remote, under-serviced area in the Canadian Arctic. Rural and Remote Health 10: 1466.

38.Gutiérrez SG, Jose MQ, Amaia $B$, Antonio E, Emilio PM, et al. (2009) Validation of priority criteria for cataract extraction. Journal of Evaluation in Clinical Practice 15: 675-684.

39.Quintana JM, Aróstegui I, Azkarate J, Goenaga JI, Elexpe X, et al. (2000) Evaluation of explicit criteria for total hip joint replacement. Journal of Clinical Epidemiology 53: 1200-1208. 


\section{Usagers PEECA - Priorisation}

Bonjour,

Ce bref questionnaire est une étape préliminaire de votre participation au projet de recherche "Exploration des déterminants de l'implantation d'un outil d'aide à la décision au sein de programmes de réadaptation". Cette première étape permet de recueillir individuellement vos perceptions par rapport aux critères de priorisation des usagers au sein du programme de réadaptation ciblé. Par la suite, vous serez invités à participer à un groupe de discussions afin d'obtenir consensus sur ces mêmes critères de priorisation.

Il y a 5 questions dans ce questionnaire

\section{Caractéristiques sociodémographiques}

Quelques questions pour avoir une idée des caractéristiques des répondants

\section{Quel est votre genre?}

Veuillez sélectionner une seule des propositions suivantes:

Homme

Femme

\section{Quel est votre groupe d'âge?}

Veuillez sélectionner une seule des propositions suivantes:

19 ans et moins

20-29 ans

30-39 ans

40-49 ans

50-59 ans

60-69 ans

70-79 ans

80 ans et plus

\section{Parmi les énoncés suivants, lequel correspond à votre situation?}

Veuillez sélectionner une seule des propositions suivantes:

Je suis en attente de services au programme d'évaluation et d'entrainement à la conduite automobile (PEECA)

Je reçois actuellement des services au programme d'évaluation et d'entrainement à la conduite automobile (PEECA)

J'ai reçu des services du programme d'évaluation et d'entrainement à la conduite automobile (PEECA)

Critère de priorisation 
Dans cette partie du questionnaire, nous vous demandons de dresser une liste de critères qui devrait être utilisé pour classer en ordre de priorité les usagers dans le programme d'évaluation et d'entrainement à la conduite automobile (PEECA). Cette liste peut inclure des critères liés à la personne (ex.: âge, genre), à sa pathologie (ex.: degré d'atteinte, douleur, niveau de dépression), à son fonctionnement

(ex.: niveau d'incapacité, capacité à marcher) ou à toute autre dimension que vous jugez pertinente (ressources du milieu, contraintes organisationnelles et légales, autre)

Selon vous, sur quels critères devrait-on se baser pour prioriser les usagers en attente de services au PEECA? Veuillez en identifier entre 5 et 10.

Veuillez écrire votre(vos) réponse(s) ici:
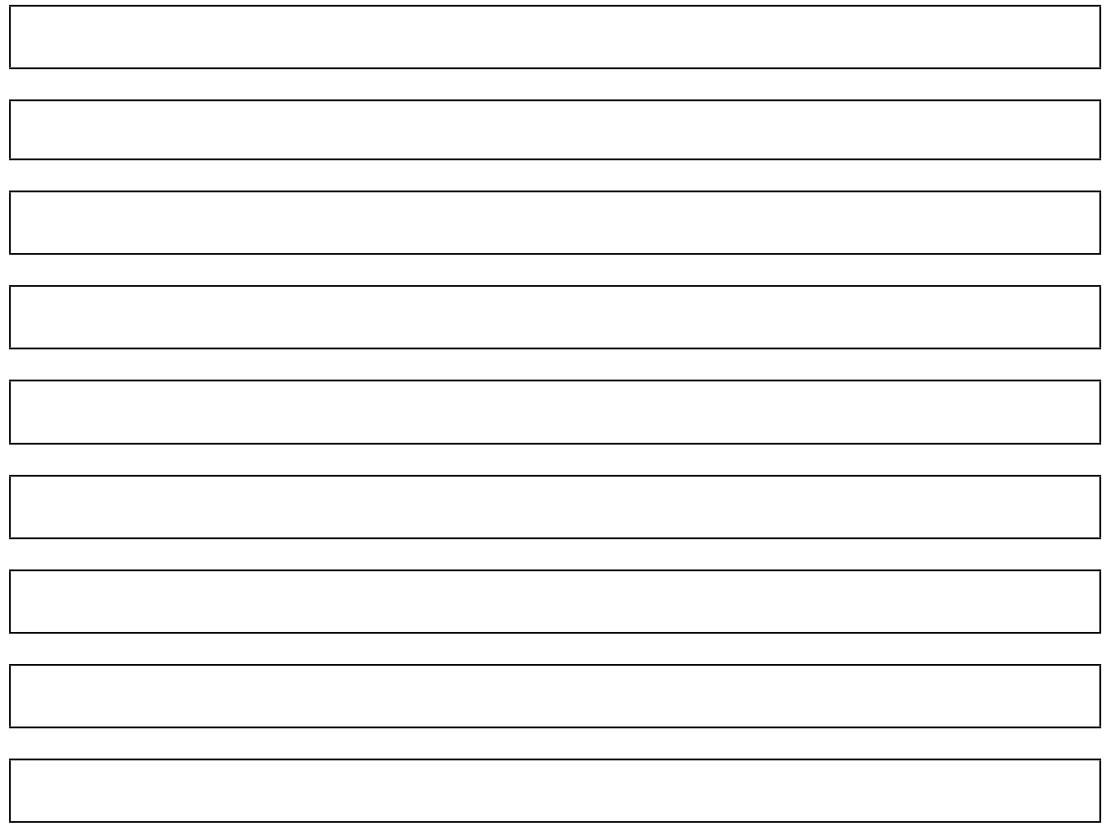

\section{Avez-vous d'autres informations ou commentaires dont vous aimeriez nous faire part?}

Veuillez é 
L'équipe de recherche vous remercie de votre participation! Vous recevrez prochainement par courriel une invitation pour le groupe de discussions.

SI vous avez des questions ou besoin d'informations complémentaires, vous pouvez joindre Julien Déry, étudiant chercheur, par courriel (julien.dery.4@ulaval.ca) ou par téléphone au (418) 529-9141 poste 6179.

Envoyer votre questionnaire.

Merci d'avoir complété ce questionnaire. 